\title{
Contemporary tendencies in higher education - application of artificial intelligence
}

\author{
Raya Ilieva $^{1 *}$ \\ ${ }^{1}$ South-West University "Neofit Rilski”, Faculty of Law and Histiry, Departament of Civil law, \\ sq."Georgi Izmirliev - Makedoncheto" 1, 2700, Blagoevgrad, Bulgaria
}

\begin{abstract}
In the 21 st century, artificial intelligence has undergone unprecedented development as a result of advances in computing power, the ability to accumulate, store and access vast amounts of data, as well as from a deeper theoretical understanding. This brings huge benefits to education, business and industry, where fundamental changes in attitudes, patterns of learning and the use of artificial intelligence to anticipate, monitor and manage risk in the dynamics of globalization and automation are observed. This article aims to explore the possibility of current trends in the development of digital technologies and globalization. The subject of the study is whether universities work in good coordination in order to be adequately prepared for the inevitable changes in society and the economy. Research methods that are used are general and specific, namely: normative, systematic, comparative analysis, induction and deduction The main task is to encourage universities to continue with their adaptation and development of their online distance learning systems, greater individualization of students' academic development, rapid exchange and application of good practices in the processes of education, management and research.
\end{abstract}

\section{Introduction}

The development of higher education is one of the main topics in the addendum of the European Union (EU) and it takes a central place in Project Europe 2030, Challenges and Opportunities. The strategy of the Union is to achieve intelligent and uniting growth in the second half of the century. The significance of higher education for the achievement of a sustainable growth is also highlighted in the Strategic Framework of European Cooperation in Education and Training (ECET 2020), according to which the challenges of the contemporary globalizing world necessitate the creation of a competitive European Economics of Knowledge [1].

The European Union is standing before a number of difficult tasks. On one hand, the life and health of young people must be guaranteed, while on the other hand there must be a sustainable development of the higher education system. The new system must set new goals matching the actual challenges connected to the accelerated development of digital

\footnotetext{
*Corresponding author: raiailieva@abv.bg
} 
technologies and to the intensive global discussion on the purposes of higher education and on the role of higher educational institutions in the new conditions.

\section{Problems, tasks, and perspectives}

We are witnesses of the acceleration of both mega tendencies - the development of digital technologies and the globalization, which means that universities have to work in a good coordination in order to be adequately prepared for the inevitable changes of the society and economics resulting mainly from the progress of technology based on artificial intelligence. According to the Europe 2030 Strategy [2], the Economics of Knowledge and Innovations are the main instruments for the achievement of intelligent growth, and the realization of this goal has to be supported by two instruments - the Innovation Union initiative and the strategies for updating the higher education systems in Europe. In these instruments, the European Commission (EC) describes the role of higher education as the basic factor for the development of national innovation systems and of the innovation cooperation within the Union.

In the $21^{\text {st }}$ century, artificial intelligence has been undergoing an unprecedented development resulting from the advancement of computer power, the opportunities of accumulation, storage, and access to a huge amount of data, as well as from the deeper theoretical understanding. This brings huge benefits to education, business, and industry, where fundamental changes are noticed in the attitude, models of learning new knowledge and skills, and use of artificial intelligence for foreseeing, monitoring, and risk management in the dynamics of globalization and automation.

Recently, the number of scientists who and the organizations which actively study this opportunity and the scientific researches in this field are extremely various. Projects like Human Brain Project [3] aim to build a functioning simulation in human brain, which will contribute to the understanding of its functionality and the processes in it and they have the potential to help for the development of general artificial intelligence. This project is among the three biggest active scientific research projects dealing with general intelligence.[4] Some higher educational institutions have already started courses of general intelligence. For example, the first such school was organized in the city of Xiamen, the People's Republic of China, in 2009, by the University Artificial Brain Laboratory and Open Cog, and the first university course in Bulgaria was organized in 2011, at Plovdiv University Paisii Hilendarski by Todor Arnaudov.

Artificial intelligence has already been extensively used in science - both in natural and in social and humanitarian sciences. Moreover, it has already been changing in fields like medicine and pharmaceutics, where it is used mainly for finding new medications, for predicting the possibility of side effects of a specific drug, for in silico testing, without the use of animals, etc. Artificial intelligence also contributes for the development of diagnostics and treatment of a number of diseases: cancer, HIV, dementia, Parkinson's disease, and many others [5]. In addition, there are great expectations on its possibilities for the development of personalized medicine, in the system of healthcare as a whole, as well as in the analyses in all scientific fields - chemistry, physics, astronomy, climate, social and humanitarian sciences, etc. [6]

Due to the high world competition and the rapid pace of development in the field, Bulgarian higher education has to be updated and transformed. Meanwhile, the focus on the so-called soft skills, emotional intelligence, etc., does not have to be lost. To improve the competitiveness of Bulgarian specialists, Bulgaria has to encourage even more international programmers in education, including the recovery and highlighting the advantages of fields like mathematics, computer science, bioinformatics, and engineering majors. Particular attention has to be paid to the active role of the government in building the connections 
between business, as a basic source of technological solutions, and the academic community. The collaboration of young scientists with international teams and the academic centres has to be supported and stimulated, as the creation of opportunities for joint diplomas and international specializations is an essential part of the process. Basic courses of artificial intelligence have to be introduced in natural and humanitarian specializations as well.

Higher educational institutions ought to make efforts to adapt to the new opportunities and challenges based on the development of digital technology. The 2020 pandemic had a significant influence on the processes of education and training. The weak points in the system became obvious. The need of rapid adaptation of the system and the processes had changeable success in the country, considering the influence of different specific factors.

Greater part of the educational and training processes continued almost without interruption, including the higher educational institutions, most of which had already had an access to online learning platforms.

It is expected that these tendencies, intensified by the pandemic conditions, are going to develop that way. This requires that higher educational institutions should continue the adaptation and development of their online learning systems, the greater individualization of the academic development of the students, the rapid exchange, and the application of best practices in the processes of education, management, scientific researches, etc. It is necessary that these processes should be encouraged, including by the government, so that Bulgarian higher educational institutions keep abreast with the European and world tendencies[7].

Considering the rapid development of artificial intelligence in the past few years and the lag of the system of formal education from the needs of the labor market, which have been changing with unprecedented pace - a challenge with a global meaning, a number of effective measures have to be taken for the improvement of the quality of education, the update of its contents, and the provision of a better connection between the educational system and the needs of the business and the society in the era of digital transformations. Three basic trends for coping with the global tendencies and challenges have to be identified:

- training connected to the development and the application of artificial intelligence;

- scientific researches in the field of artificial intelligence;

- using artificial intelligence systems within professional education and training, lifelong learning, higher education, and science, in order to improve the educational and scientific research process.

The strategic goals of the educational and scientific system in the country have to be focused on the adequate compensation of each of these trends, striving to increase the competitiveness of Bulgarian education, within the meaning of appropriate skills, professional and personal realization, and adequate participation in the society, and thence - the general competitive position of national economics.

Higher education must be the centre of integrating educational instruments with artificial intelligence, which has to encourage the wide use of digital instruments based on artificial intelligence not only in educational processes, but also in the administration of the higher educational institutions, some of which could also be introduced in secondary education [8].

High technological secondary professional education has to find its solution in innovative educational models which integrate high technological professional education with higher education, with the support of the business and industry. This symbiosis supposes opening the teacher's profession to the current high technology experts from the business and lecturers from the higher educational institutions. This way, the extreme deficits of teachers in specific dynamically developing disciplines and technological fields 
may be addressed. Business experts could show the latest trends of technological world, together with the personal role model, initiative, and professional success in the classrooms. Lecturers from higher educational institutions may bring academic spirit, creativity, motivation, and perspective so that each student could continue their way to the academic environment [9].

It is necessary to create platforms for the whole educational spectrum, which platforms have to cover and connect pre-school with secondary and higher education, and based on the feedback questionnaires, the educational levels and needs of their uses would be made more precise. Like Kindle, through which Amazon collects information on how readers react to a particular text, similar solutions can be expected from the educational platforms as well, so that they could foresee and assess whether the content has been understood well and, if necessary, they could adapt their systems to the specific user. On one hand, this would contribute to the equal access (even for children who do not speak foreign languages) and reinforce the idea of the Internet and technologies as free 'abundance' of knowledge. On the other hand, this would support the continual trends of the modernization of the classical forms of education, especially of the higher one. This would also concern secondary education, which has a key socializing function.

The government has to establish a cooperation practice with the other member states of the EU for the exchange of students, teachers, and scientists. The effect of the so called smart classrooms and academic halls has already been observed. This contributes to the increased efficiency of training and promotes personal approach, which matches the unique needs of each school and university student, as well as of the administrators, and opens opportunities for the optimization of the education, through a set of respective complicated analytical studies. All this has to be supported by the teachers and the lecturers ought to have enough time and freedom to concentrate on their own understanding and its adaptation to the new knowledge for the students. The Ministry of Education and Science may initiate a pilot construction and use of smart classrooms in some higher educational institutions, as, after the assessment of the efficiency, it may initiate their pilot construction and use in a limited number of innovative schools.

Considering the rapid invasion of new technologies in people's everyday life, the modernization of the technological and methodological aspect of education is a must. New generations worldwide tend to look for and use IT-based learning platforms not only in classrooms, but also in their self-study. In this sense, the integration of the so called blended learning, including instruments with artificial intelligence for online learning, is inevitably on the basis of the future of educational systems. This is particularly important for the higher education system, as well as for the lifelong learning, which develops and encourages the opportunity of self-studying, blended learning, etc. [10], so that training may happen anywhere, anytime, including out of the formal educational systems.

Online platforms with educational resources in the field of artificial intelligence - the platforms have to allow adequate environment for mass online courses and for storage of a wide range of educational materials - online textbooks, video lectures, tests, games, virtual laboratories, and virtual classrooms. Due to the specifics of AI, different environment for writing and execution of codes for testing and educational purposes has to be foreseen (the so-called sandboxes). This would allow an interactive form of education, in which students would directly write and test small programmes as the first step to the construction of an adequate artificial intelligence [11].

It is recommended that these platforms should use artificial intelligence for teaching students. This would additionally help students in gaining knowledge and practical skills and would generate a potential for the developed use of artificial intelligence in higher education. 
Integration of analytic models based on artificial intelligence in the online learning platforms of higher educational institutions and public scientific organizations. Analytic modules would be used in two basic tasks: the first one includes analysis of the presentation of different students, lecturers, programmes, and universities as well as creation of personalized curriculums in the field of artificial intelligence of each student, which report the specific needs and the level of the respective student [12].

Creation of a unified national educational platform which is to integrate the domestic systems of the higher educational institutions and the research institutions, which platform would allow transfer of courses and credits in the field of artificial intelligence and the connected disciplines between different institutions. Such a system is the first step to the unification of the educational and scientific potential in scientific clusters with specific research programmers [13].

\section{Conclusion}

Not only for Bulgarian education, but also worldwide, quarantine and self-isolation measures have served as a catalyst for digitalization and a chance to modernize the education system.

The tendencies of higher education development, the policies of the European Union, as well as the dynamic European Higher Education Area place a number of challenges before the higher educational institutions in Bulgaria. The internationalization and globalization, the decreasing public funding, the increasing number of students, and their increasing requirements on one hand, and the increasing competitions, the requirements for quality, the digitalization as a process on the other hand, outline new opportunities and requirements towards the universities.

The classroom of the future includes interactive whiteboards, laptops, tablets, phablets, smartphones, programmable drones, robots and more. Such equipment for the training of future specialists in higher education is a matter of financial resources and to some extent is a problem for all European countries. University professors are still afraid of using information and communication technologies (ICT) or cannot handle them well. It is imperative that universities create and provide an appropriate environment, and teachers need to seek and implement new ICT learning strategies.

In this direction, several recommendations can be outlined for improving the teaching and academic environment for the development of good practices in education.

1. The classroom of the future includes interactive whiteboards, laptops, tablets, phablets, smartphones, programmable drones, robots and more. Such equipment for the training of future specialists in higher education is a matter of financial resources and to some extent is a problem for all European countries. It is imperative that universities create and provide an appropriate environment, and teachers need to seek and implement new ICT learning strategies.

2. Modern research shows unequivocally that the dominant global theoretical and methodological platform of e-learning is constructivism with its deeply humane and developing meaning.

3. The aspiration must be directed towards the development of higher education, by updating the content, methods and forms of education; accelerated modernization and digitalization of educational approaches, methods and practices, only in this way they will respond to a dynamic, competitive and changing external environment.

Many of the outlined problems remain to be solved. However, raising them will make it possible to fully understand the nature of modern transformation and meet the challenges of the information society. 


\section{References}

1. R. Moreno, R. Mayer, Interactive multimodal learning environments: Special issue on interactive learning environments: Contemporary issues and trends. Educational Psychology Review 19 (3), 309-326 (2007).

2. MTITC (2020). Digital transformation of Bulgaria for the period 20202030.www.mtitc.government.bg/sites/default/files/digital_transformation_of_bulgaria_f or_the_period_2020-2030_f.pdf

3. Flint, K.. Lundin, G. Höst, and K. Schönborn, Virtual nano worlds for learning, In D., K. (eds), Virtual Nanoworlds for Learning, Boca Raton: CRC Press; (2020)

4. K. Schönborn, G. Höst, Lundin Palmerius. Nano education with interactive visualization. Nano Today blication. Nanotoday 11 (5), (2016)

5. R. Garrison, Online community of inquiry review: Social, cognitive, and teaching presence issues. Journal of Asynchronous Learning Networks 11 (2007).

6. K. Schönborn, G. Höst, K. Palmerius, and J. Flint, Development of an interactive immersion environment for engendering understanding about nanotechnology: concept, construction and implementation. Int. J. Virt. and Pers. Learn. Envir, 5 (2014).

7. T. Bates, C. Cobo, O. Mariño, and S. Wheeler, Can artificial intelligence transform higher education? Int. J. Educ. Technol. High. Educ. 17 (2020).

8. P. Jaimes, J. Libarkin, D. Conrad, College Student Conceptions about Changes to Earth and Life over Time, CBE_-Life Sciences Education 19, 3 (2020)

9. R. Milkova,Strategies for policy in science and education educational journal, Competency and Skills of the Person - Strategy of University Education During XXI Century 23, 38-64, (2015)

10. P. Ivanov, Strategies for policy in science and education educational journal, Strategies for policy in Science and Education journal 23, XXIII, 590 - 611 (2015).

11. Bayne, S. Teacherbot: interventions in automated teaching. Teaching in Higher Education 20(4), (2015)

12. X. Chen, Y. Wang, M. Nakanishi, X.Gao, TP. Jung, and, S. Gao, High-speed spelling with a noninvasive brain- computer interface. Proceedings of the National Academy of Sciences, 112(44), E6058-E6067, (2015)

13. V. Koval, Y. Polyezhayev, and A. Bezkhlibna, Communicative competences in enhancing of regional competitiveness in the labour market, BJES 4, 105 (2019). 